\title{
Comparison of Abstracts Written by Native Speakers and Second Language Learners
}

\author{
Xiaoli Ji \\ Jiangsu University of Science and Technology, Zhenjiang, China \\ Email: jixiaoli2005@126.com \\ Received 21 April 2015; accepted 16 October 2015; published 19 October 2015 \\ Copyright (C 2015 by author and Scientific Research Publishing Inc. \\ This work is licensed under the Creative Commons Attribution International License (CC BY). \\ http://creativecommons.org/licenses/by/4.0/ \\ c) (i) Open Access
}

\begin{abstract}
As an ideal vehicle for projecting news value, the journal abstract appears to be growing in importance, as noted by a number of writers, but the studies are still not enough, especially comparison study between the abstracts written by native speaker and second language learner. So this paper tries to find out both similarities and differences in structure of abstracts from these two groups through genre analysis of two corpuses: one for abstracts from native speakers, the other for abstracts from Chinese English learners. The results indicate that the Chinese learners focus too much on introduction move and can't use tense properly in all cased. This result leads us to consider the teaching of writing for special purpose.
\end{abstract}

Keywords

Abstracts, Swales IMRC (Introduction, Method, Results, Conclusion) Model, Genre Analysis

\section{Introduction}

As one of the important parts of paper, abstracts foreground important information for easy access, serve as an early screening device, frame the reading of the article they accompany and provide a summary of the main points of the article for later reference (Berkenkotter \& Huckin, 1995). Thus as an ideal vehicle for projecting news value, the journal abstract appears to be growing in importance, as noted by a number of writers. It has also been studied by Chinese scholars such as Ju (2004), Ge \& Yang (2005) and Yu \& Liang (2006) in recent years, but the studies are still not enough, especially comparison study between the abstracts written by native speaker and second language learner. So this paper tries to find out both similarities and differences in structure of abstracts from these two groups through genre analysis.

\section{Theoretical Basis}

Any study of language or, more specifically, text at a level of above that of a sentence is a discourse study. This 
may involve the study of cohesive links between sentences, of paragraph structure or the structure of the whole text. The results of this type of analysis make statements about how texts-any texts-work. This is applied discourse analysis. Where, however, the focus of the text analysis is on the regularities of structure that distinguish one type of text from another type. Bazerman (1988: p. 58) sees the abstract as a representation: "The article's abstract serves as one further step in turning the article into an object, for the abstract considers the article as a whole and then makes a representation of it”. The research of Swales (1990) also finds that the abstract has the same structure as the whole article, on the basis of this, he proposed IMRC model (see Figure 1). Abstracts are generally seen to have a fairly predictable four-part structure-Introduction-Methods-Results-Conclusion/ Discussion (IMRC/D) (as traditionally does the full article).

\section{The Selection of Corpus}

On the basis of this model, this paper tries to make comparison of the structure of abstracts from two corpuses. The first corpus (Corpus A) has 30 abstracts written by native speakers collected from one international conference while the second (Corpus B) has 30 abstracts from Chinese scholars in the same conference. There are three reasons for these: first, as a volunteer of the conference, it is easy for me to collect the corpus. Second, because all the abstracts come from the same conference, they have the same topic, language testing, so the influence of topic and discipline can be delimited. Third, most of these scholars have relatively high language proficiency.

\section{The Analysis of the Structure}

First, the frequency of each move in the abstracts was counted (see Table 1).

From the above table, we can see for the abstracts from the native speakers, the focus of the communicative goals is on Research Method and Research Result, which could be very useful for the authors to express different methods and results, the same as the introduction (Swales, 1990: p. 141) in which the recursion results from the two moves, establishing a niche and occupying the niche. But the Chinese learners put more attention on introduction while neglecting research method. This can be seen not only from the frequency but also from the length for each move. The first move of the abstracts from Chinese is longer than the ones from native speakers.

\begin{tabular}{|l|}
\hline \multicolumn{1}{|c|}{ The structure of abstract } \\
Move 1 Introduction \\
Step 1A Claiming Centrality \\
Step 1B Topic Generalizations and Reviewing of Previous Research \\
Step 1C Indicating a Gap \\
Step 1D Outlining Purpose \\
Step 1E Announcing Present Research \\
Move 2 Methods \\
Move 3 Results \\
Move 4 Conclusion \\
Step 4A Commenting on Results \\
Step 4A i.Interpreting Results \\
Step 4A ii Comparing Results with Literature/Previous Findings \\
Step 4A iii Accounting for Results \\
Step 4A iv Evaluating Results \\
Step 4B Commenting on the Study \\
Step 4B i Indicating Significance/Advantage \\
Step 4B ii Deduction from the Research \\
\hline
\end{tabular}

Figure 1. Swales IMRC model.

Table 1. The frequency of each move for in the abstracts.

\begin{tabular}{ccccc}
\hline & Move 1 & Move 2 & Move 3 & Move 4 \\
\hline Corpus A & 23 & 25 & 27 & 19 \\
Corpus B & 27 & 18 & 28 & 12 \\
\hline
\end{tabular}


Here are two examples for Move 1 from the two corpuses:

Example 1 (from corpus A): The introduction of modern test theory in the field of language testing has raised the awareness among practitioners of unidimensionality as a basic requirement for measurement. (Step 1B Topic Generalizations and Reviewing of Previous Research) The concept, however, has led and continues to lead to debates and misunderstandings. (Step 1C Indicating a Gap) In this paper we will present data form a large scale research project involving over 6000 subjects with more than 90 different language backgrounds... (Step 1E Announcing Present Research)

Example 2 (from corpus A): In order to implement an effective foreign language program, it is very important to determine student placement based on their true language knowledge as opposed to how much "seat time" instruction they have had. (Step 1C Indicating a Gap) This paper describes the design of a listening exam and investigates validity issues using Bachman's (2005) framework of an assessment use argument. (Step 1E Announcing Present Research) The purpose of this study is twofold: First, to interpret the listening scores for the listening exam as a way to know what test-takers can do and, second, to place students in Spanish classes. (Step 1D Outlining Purpose)

Example 3 (from corpus B): Cambridge Young Learners English (YLE) test has been gaining an increasing popularity around the world over the past decade. However, the specific characteristic of children as language learners and test-takers tends to make young learners' tests a controversial issue. There is always the tension between a positive impact and test fairness, particularly in the speaking component of the YLE test. On the onehand, to remain committed to giving children a positive experience of testing and to encouraging their future language learning, the YLE test has a requirement for intended positive washback and impact. Taking this into consideration, it seems natural for the YLE oral examiner to resort to some elements other than the candidate's performance in rating. On the other hand, for the sake of test fairness, score accuracy and reliability must be ensured. (Step 1C Indicating a Gap) Driven by a desire to justify the usefulness of YLE speaking test to the test-takers and their teachers, (Step 1D Outlining Purpose) this study attempts to address the elements beyond the particular speaking scoring criteria, and whether and how they may influence oral examiners' marking. (Step 1E Announcing Present Research)

Example 4 (from corpus B): The College English Test (divided into CET-4 and CET-6) is a nation-wide highstakes English test in China, administered by the National College English Testing Committee of China. Since its first implementation in 1987, CET has gone through 20 years of development. In January 2004, the Ministry of Education of China issued the newly enacted College English Curriculum Requirements and began the pilot work of college English reform. Accordingly, reform on CET has been carried out and the new CET-4 made its first appearance in June, 2006. Though the old CET has attracted great attention among researchers and language teachers and has already established its authority (see for example, Yang and Weir, 1998), the new one has stirred little research interest so far. (Step 1C Indicating a Gap) The writers of the present paper, therefore, have conducted a study to investigate the comparability of the old and new CET-4, aimed at answering the following research questions:

1) To what extent is the new CET-4 comparable to the old one in terms of content, format and test taker performance?

2) Which test better measures Chinese students' communicative language ability?

3) What are the main problems concerning the implementation of the new CET-4?

(Step 1E Announcing Present Research)

It can be inferred from the above that the Chinese learners spend too many words to indicate the gap by providing abundant background knowledge while the native speaker focus on Announcing Present Research. The other distinctive difference between the two corpuses is Move 2 Methods. For most of the Chinese scholar, this move is neglected or combined into Move 3 Result. So the native speakers try to express how to do the research and the result while Chinese English learners focus on why to do the research and the result. But there is one exception, one of the Chinese learners even doesn't have the introduction move (see example 5).

Example 5 (from corpus B): The present study, within Messick's unitary validity conception, collects theoretical and empirical evidence for the substantive and generalizability aspects of construct validity of the textbased writing task in National Matriculation English Test (Guangdong Version), a newly-designed large-scale high-stakes test in China. It adopted a constructivist reading-to-write model specifying the metacognitive (planning and monitoring) and cognitive (selecting, organizing, and integrating) operations elicited in text-based 
writing.

In fact, some abstracts, especially the abstracts from the Chinese learners, don't include all the four moves in Swales model. From Table 2, we can see that the abstracts from corpus A are generally more complete than the ones from corpus B.

\section{The Analysis of Tense}

Apart from the structure, the linguistic features, mainly tense and voice have also been analyzed. The number of modal verbs in each move, the three categories of tense (present tense, past tense, present perfect tense) have been calculated. Then the values obtained in this way are compared and analyzed.

It can be seen from Table 3 that the Chinese learners' abstracts are different greatly from the native speakers' in the aspect of tense.

For Move 1, the native speakers tend to use the present tense while the Chinese learners to use the present perfect tense. But “... if writers use the past tense in reporting research done previously by themselves or by others then that research is of secondary importance to the current work being reported on. If, on the other hand, the writer uses the present perfect or the present tense, then the research is of more direct and primary importance to the writer's current work. Also, the present tense is often chosen when a discussion follows the initial citing of a reference to their own or the others' research and/or when important generalizations are being expressed."

For Move 2, the Chinese learners have used more present perfect tense. A major criterion for determining tense choice in the rhetoric of description: "If the object being described is still functioning as a useful device at the time someone writes about it, the writer will use the present tense. If, on the other hand, the object being described is no longer in use, then the writer will use the past tense." So the use of present perfect tense is not proper here.

For Move 3, the Chinese learners use the present tense and the past tense equally while the native speakers tend to use the present tense. Apparently, the two groups have no difference in Move 4.

\section{Conclusion}

From the analysis of the structure and the tense, we find out that the abstracts written by the Chinese scholars are quite different from the native speakers. From the perspective of the structure, the Chinese learners focus on introduction and result while the native speakers pay attention on method and result. Also it is rare for the Chinese learners to include all the four moves of the abstracts. The tense is another problem for them. Hopefully, the findings of the thesis may have some implications for teaching English for Academic Purposes (EAP) and

Table 2. The frequency for the abstracts with different amount of moves.

\begin{tabular}{ccccc} 
& Four moves & 3 moves & 2 moves & 1 move \\
\hline Corpus A & 7 & 15 & 8 & 0 \\
Corpus B & 1 & 13 & 14 & 3 \\
\hline
\end{tabular}

Table 3. The frequency of tense in each move.

\begin{tabular}{|c|c|c|c|c|c|}
\hline & & Move 1 & Move 2 & Move 3 & Move 4 \\
\hline \multirow{2}{*}{ Present tense } & Corpus A & 39 & 66 & 81 & 26 \\
\hline & Corpus B & 15 & 50 & 40 & 23 \\
\hline \multirow{2}{*}{ Past tense } & Corpus A & 5 & 15 & 33 & 2 \\
\hline & Corpus B & 7 & 15 & 45 & 0 \\
\hline \multirow{2}{*}{ Present perfect tense } & Corpus A & 15 & 1 & 5 & 0 \\
\hline & Corpus B & 41 & 17 & 4 & 2 \\
\hline
\end{tabular}


English for Specific Purposes (ESP). But the research is far from enough, the corpus is too small, and the abstracts are all from the same discipline. Further study might be conducted to make comparison among the different discipline to find out more differences.

\section{Funding}

This paper is funded by the school funded project, the project number is 10782010102 .

\section{References}

Bazerman, C. (1988). Shaping Written Knowledge: The Genre and Activity of the Experimental Article in Science. Madison: University of Wisconsin Press.

Berkenkotter, C., \& Huckin, T. N. (1995). Genre Knowledge in Disciplinary Communication: Cognition/Culture/Power. Hillsdale, NJ: Lawrence Erlbaum.

Ge, D. M., \& Yang, R. Y. (2005). A Genre Analysis of Research Article Abstracts. Modern Foreign Language (Quarterly), 28, 138-146.

Ju, Y. M. (2004). A Genre Analysis of English and Chinese Research Article Abstracts. Foreign Language Education, 25, 32-36.

Swales, J. (1990). Genre Analysis: English in Academic and Research Settings. Cambridge, UK: Cambridge University Press.

Yu, L., \& Liang, Y.G. (2006). The Writing Style of English Research Article Abstracts. Foreign Language Education, 27, 34-37. 